\title{
The solid ingredient properties influence on the energy characteristic of the coal-water slurry fuel flow
}

\author{
Nataliia Chernetska-Biletska ${ }^{1}$, Hanna Shvornikova, ${ }^{1, *}$, Kostiantyn Podoliak $^{2}$, Serhii \\ Kyrychko $^{2}$, and Mariia Miroshnykova ${ }^{1}$ \\ ${ }^{1}$ Volodymyr Dahl East Ukrainian National University, 93400, Severodonetsk, Tsentralnyi Ave., 59a, \\ Ukraine \\ ${ }^{2}$ Institute of Geotechnical Mechanics named by N. Poljakov of National Academy of Sciences of \\ Ukraine, 49005, Dnipro, Simferopolska Str., 2a, Ukraine
}

\begin{abstract}
The article analyses the process of making the coal-water slurry fuel. The main factors influencing the slurry rheological characteristics and, therefore, energy costs during its transportation are determined. The main attention is paid to the original coal ash content efficiency influence on the energy characteristics of the coal-water slurry fuel. In the work, the transformations of classical rheological equations were carried out taking into account the experimental dependence of the coal-water fuel effective viscosity on the feedstock ash content. As a result of the conducted transformations the dependence to determine the specific pressure loss due to the feedstock ash content was obtained. This has enabled to supplement the eligibility determination techniques for the grade of the coal used as the feedstock for the preparation of the coal-water fuel with rational energy and rheological characteristics. To substantiate the theoretical calculations, the article presents the results of the experimental studies on the effect of coal ash content on the specific pressure losses.
\end{abstract}

\section{Introduction}

The trouble with energy supply to the enterprises and population of Ukraine is becoming increasingly important. This is primarily due to the shortage of liquid and gaseous fuel, which also affects its cost. Therefore, increasing interest in the use of alternative types of energy carriers in small and medium-sized power-industry is quite natural.

The most promising is to increase the use of fuels based on the coal component. However, when creating alternative coal fuels, it is imperative to consider the environmental limitations. Thus, modern coal technologies must ensure high completeness of fuel use, cost-effectiveness, reliability, safety of use and minimal environmental impact.

This problem can be solved by enhancing the use of the coal-water slurry fuel (CWSF). This will solve a number of issues related to the transportation of coal by more costeffective pipeline transportation. This excludes losses, associated with deterioration of fuel

${ }^{*}$ Corresponding author: shvorni@gmail.com 
quality: oxidation, weathering, dusting, freezing, etc.

The coal-water slurry fuel contains $60-70 \%$ of coal $10-200$ microns in size, $30-$ $40 \%$ of water and $1 \%$ of a chemical reagent-plasticizer. The ignition temperature of the CWSF is $450-650{ }^{\circ} \mathrm{C}$, the combustion temperature is $950-1050{ }^{\circ} \mathrm{C}$, and the burnout rate is up to $99.5 \%$. Such favourable conditions for combustion contribute to a significant reduction in the combustion products of nitrogen oxides, carbon monoxide and benzo[a]pyrene (by 5 times) $[1,2]$.

The coal-water slurry fuel can be produced from anthracite, bituminous and brown coal of various grades and ash content, water of any quality, including mine and industrial water. In addition, other substances can be used as carrier fluid, for example, magnetic or other polar liquids.

The suitability of the coal for the CWSF preparation is generally determined by: carbon content, volatile substance, intrinsic moisture, calorific value, as well as oxygen/carbon, hydrogen/carbon, nitrogen/carbon ratios, and grinding ratio. As shown by numerous studies $[3,4,5]$, the most important indicator for the CWSF preparation is the active oxygen content.

The main technological characteristics of the coal-water slurry fuel are calorific value, fluidity and sedimentation stability during long-term storage. The fuel caloric value increase reduces the unit costs of its combustion, helps to reduce emissions of harmful substances into the atmosphere.

The CWSF calorific value improvement can be achieved by increasing the solids content in the slurry and reducing the ash content of the solid phase.

The decrease in the ash content of the CWSF solid phase is associated with the selection of the optimal technological enrichment scheme. Processes using apolar reagents have a negative impact on the rheological parameters and, consequently, energy costs during the transportation of the coal-water fuel $[6,7]$.

An important component in the selection of the raw materials for the CWSF preparation is economic feasibility. The use of energy-intensive enriching processes may adversely affect the cost of the final product. It is also necessary to take into account the effect of the degree of desalting on the fluidity and stability of the coal-water slurry. In this regard, it was decided to conduct studies of the coal-water fuel prepared from the raw Donbas coals.

Thus, the determination of the dependence of the rheological parameters and energy costs for the transportation of the coal-water fuel on the composition and ash content of the solid phase is an actual scientific and practical task and the purpose of this study.

\section{Methods}

The main criterion for the CWSF quality is the value of the effective viscosity at a given concentration or concentration at a certain viscosity, which provide the necessary stability of the fuel during storage, transportation and combustion.

As a result of the research, it was found that the coal-water fuel viscosity values should be in the range of $0.5-1 \mathrm{~Pa} \cdot \mathrm{s}[1,3,5,8]$. In accordance with the recommendations $[1,9$, $10]$, when used in coal-fired power plants, the CWSF viscosity should not exceed $1.0 \mathrm{~Pa} \cdot \mathrm{s}$, and when used in boiler rooms viscosity should not exceed $0.6 \mathrm{~Pa} \cdot \mathrm{s}$.

Considering that the energy expenditures for transportation are determined by the specific pressure loss in the hydrotransport system pipelines and are directly dependent on the viscosity and, therefore, on the ash content of the CWSF. To determine the feasibility of the chosen certain grade of the coal as a feedstock for the preparation of the coal-water fuel, it seems necessary to obtain dependencies linking pressure loss with ash content.

When considering the coal-water fuel as a homogeneous non-Newtonian fluid, the power law of the Ostwald-de Waele model and the Shvedov-Bingham model were 
considered as the main models. The generalizing Herschel-Bulkley model was often used (Table 1). When describing the coal-water fuel flow by the power dependence of the shear stress on the strain rate, the main parameter to be determined was the structural number $n$ (exponent at the velocity gradient) and the corresponding viscosity model corresponding to that number. From these two parameters depend as the Reynolds number as the coefficient of hydraulic resistance and, ultimately, the value of specific pressure losses at the CWSF hydraulic transportation.

Table 1. Rheological Models of the Coal-Water Fuel [11, 12, 13].

\begin{tabular}{|l|c|}
\hline \multicolumn{1}{|c|}{ The Name Of The Model (Law) } & Formula (Equation) \\
\hline 1. Ostwald-de Waele & $\tau=k \cdot \dot{\varepsilon}$ \\
\hline 2. Shvedov-Bingham model & $\tau=\tau_{0}+\mu_{p}|\dot{\varepsilon}|$ \\
\hline 3. Herschel-Bulkley model & $\tau=\tau_{0}+A|\dot{\varepsilon}|^{n}$ \\
\hline
\end{tabular}

Note: $\tau_{0}, \dot{\varepsilon}$ - the shear stress and shear rate; $\tau_{0}$ - the yield stress; $\mu_{p}$ - plastic viscosity coefficient; $k, n, A$ - rheological constant parameters.

All rheological studies necessarily include shear stress measurements. The viscosity is determined from the measured values of stress and shear rate. This suggests that viscosity is an ambiguous parameter. It is called "conditional" or "effective" [10]. Its value depends on many factors: the concentration of the coal solid particles in the slurry and their particle size distribution, the grade and amount of chemical additives, the CWSF transportation velocity, and the physicochemical properties of the feedstock.

Analytical determination of viscosity is not possible due to the lack of rigorous mathematical models of the interaction of various media in CWSF $[11,14]$. Therefore, the calculations use different, often not systematic experimental data, empirical dependencies. Errors of the empirical dependences are not indicated, the scope of their application is also often not given in the works.

Determining the analytical dependencies of the rheological models parameters on viscosity and the affecting it factors is one of the main tasks in the study of the CWSF rheological behaviour as it moves along a pipeline.

For liquids described by the Ostwald-de Waele equation, the values of dynamic and effective viscosity are usually determined. Dependence for dynamic viscosity has the following form $[3,15]$ :

$$
\mu_{d}=\frac{d \tau}{d \dot{\varepsilon}}
$$

or

$$
\mu_{d}=k \cdot n \cdot \dot{\varepsilon}^{n-1}
$$

The value of the effective viscosity is a consequence of Newton's viscous friction law and is described by the equation $[2,3,7]$ :

$$
\mu_{e f}=\frac{\tau}{\dot{\varepsilon}}
$$


Considering the Ostwald-de Waele equation, the expression for effective viscosity can be written as:

$$
\mu_{e f}=k \cdot \dot{\varepsilon}^{n-1},
$$

therefore, from equations (3) and (4) the relationship between the values of dynamic and effective viscosity can be given as:

$$
n=\frac{\mu_{d}}{\mu_{e f}}
$$

It was previously noted that the CWSF viscosity depends on the properties of the original coal. One of the main parameters characterizing the properties of the original product is the ash content $A^{d}$. The ash values are different for each specific grade of coal.

For experimental verification, the A and G coal grades of the Donetsk basin was used.

The ball mills were used for the preparation of prototypes, viscosity measurements were carried out using a rotational viscometer, calibrated with standard liquids.

The Figure 1 shows the approximate dependence diagram the CWSF effective viscosity on the ash content of the feedstock, and Figure 2 presents a graph of tangent shear stress vs. shear rate gradient [8]. There is accordance between the two graphs in the figures.

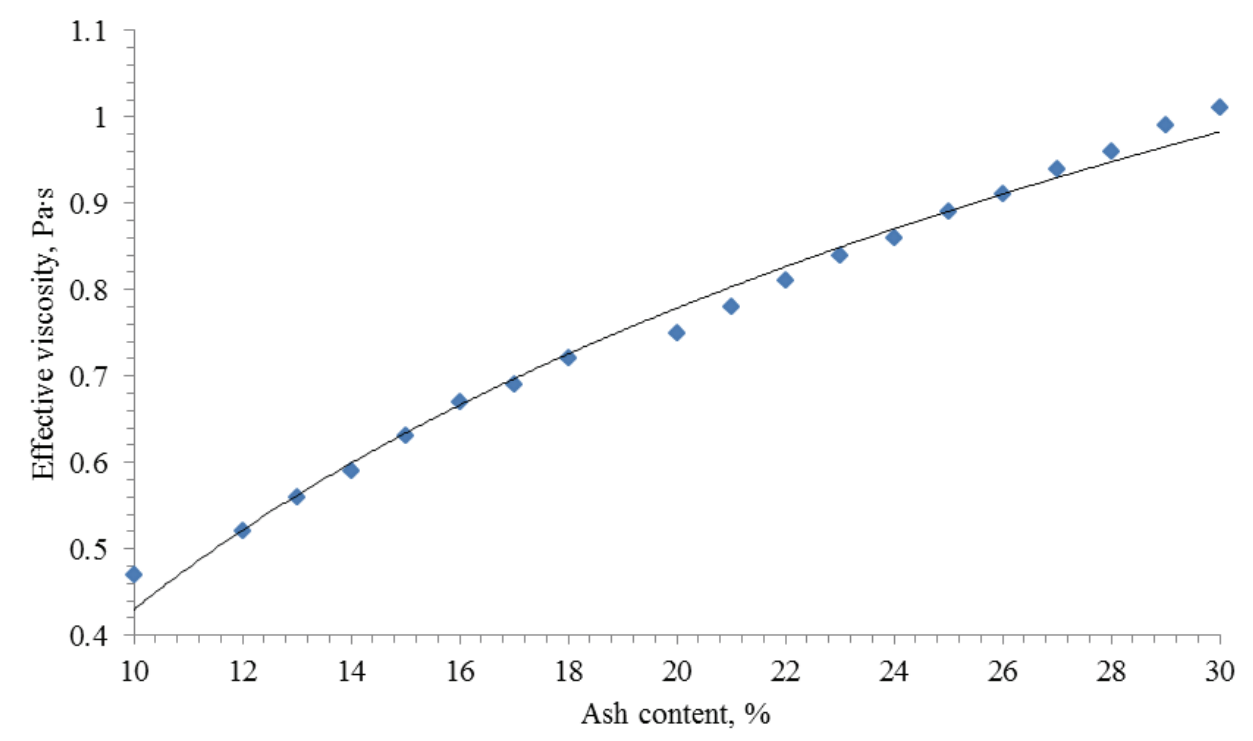

Fig. 1. The dependence of the CWSF effective viscosity on the ash content of the coal.

The curve presented in Figure 1 is described by the following function of the dependence of the effective viscosity on the ash content:

$$
\mu_{e f}=0.5033\left(\ln A^{d}\right)-0.729 \text {. }
$$

Graphical differentiation of the dependences presented in Figure 2 allows obtaining the value of the dynamic viscosity $\mu_{d}=C_{\mu_{d}}$ as an expression (1). 


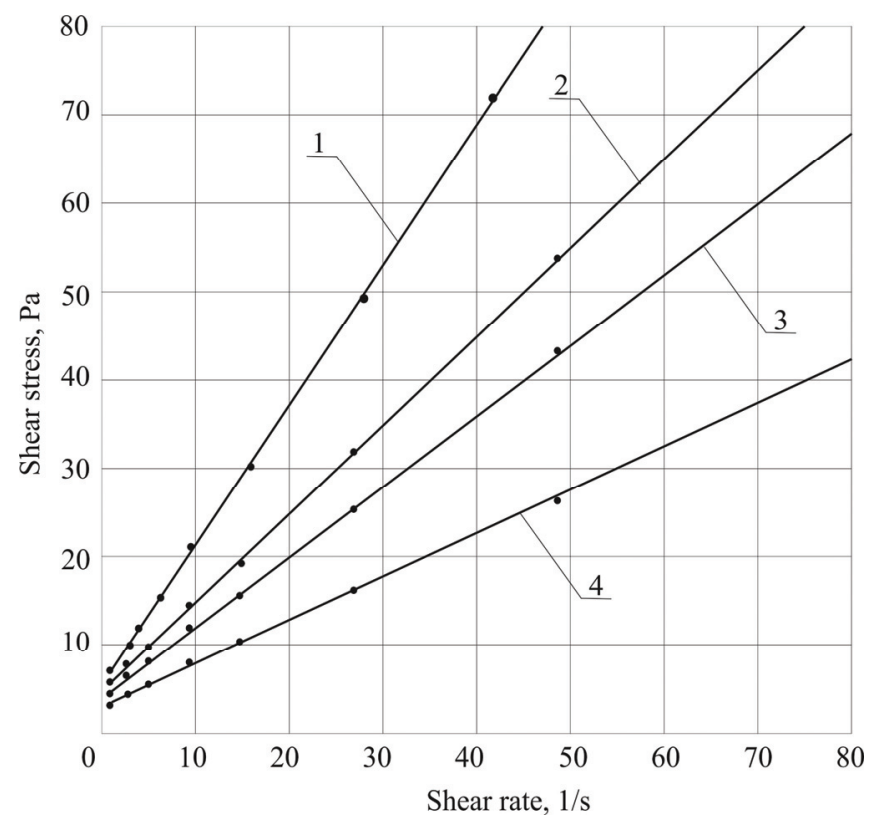

Fig. 2. The dependence of the tangential stresses in CWSF, made of the "A, G" coal grades, loaded $65 \%$ from the gradient shear rate at different temperatures: $1-5^{\circ} \mathrm{C}, 2-10^{\circ} \mathrm{C}, 3-15^{\circ} \mathrm{C}, 4-20^{\circ} \mathrm{C}$.

Then, taking into account expression (6), the dependence for the flow index on the effective viscosity can be written as:

$$
n=\frac{C_{\mu_{d}}}{0.5033\left(\ln A^{d}\right)-0.729} .
$$

Taking into account the Ostwald-de Waele model, the dependence of the consistency coefficient $k$ on the ash content of the original coal can be determined as follows:

$$
k=\frac{\tau}{\dot{\varepsilon}^{n}}=\frac{\tau}{\dot{\varepsilon}^{\left[C_{\mu_{d} / 0.5033\left(\ln A^{d}\right)-0.729}\right]}} .
$$

Denoting the denominator of the expression (8) with the variable $N$, we obtain the dependence:

$$
k=\frac{\tau}{N} .
$$

The graph presented in Figure 2 and dependencies (8) and (9) shows that the coefficient $k$ is a function of the ash content in the feedstock $k=f\left(A^{d}\right)$, and therefore depends on the grade of coal.

The possibility of the CWSF efficient transportation substantially depends on the energy consumption, which in terms of the rheology is characterized by specific pressure losses $\Delta p / L[3,8,10,16]$.

The integration of Newton's viscous friction law leads to the well-known in fluid mechanics the Hagen-Poiseuille equation (Table 1): 


$$
Q=\frac{\pi R^{4} \Delta p}{8 \mu L}=\frac{\pi D^{4} \Delta p}{128 \mu L},
$$

where $R$ - the pipe inside radius, $\Delta p$ - is the pressure difference between the two ends in the pipe length $L, D=2 R$ - the pipe inside diameter.

From the formula (10) the coefficient of dynamic viscosity is expressed:

$$
\mu_{d}=\frac{\pi D^{4} \Delta p}{128 Q L}=\frac{D \Delta p / 4 L}{32 Q / \pi D^{3}}
$$

In the numerator of the formula (11) there are expressions for $\tau$, and in the denominator for $\dot{\varepsilon}$, i.e.

$$
\tau=\frac{D \Delta p}{4 L}
$$

and

$$
\dot{\varepsilon}=\frac{32 Q}{\pi D^{3}}
$$

Taking into account the expressions (9) and (11), it is possible to obtain the dependence for specific pressure losses along the pipeline length on the ash content of the feedstock:

$$
\frac{\Delta p}{L}=\frac{4 k N}{D}=\frac{4 k \dot{\varepsilon}^{\left[C_{\mu_{d}} / 0.5033\left(\ln A^{d}\right)-0.729\right]}}{D} .
$$

\section{Results and discussion}

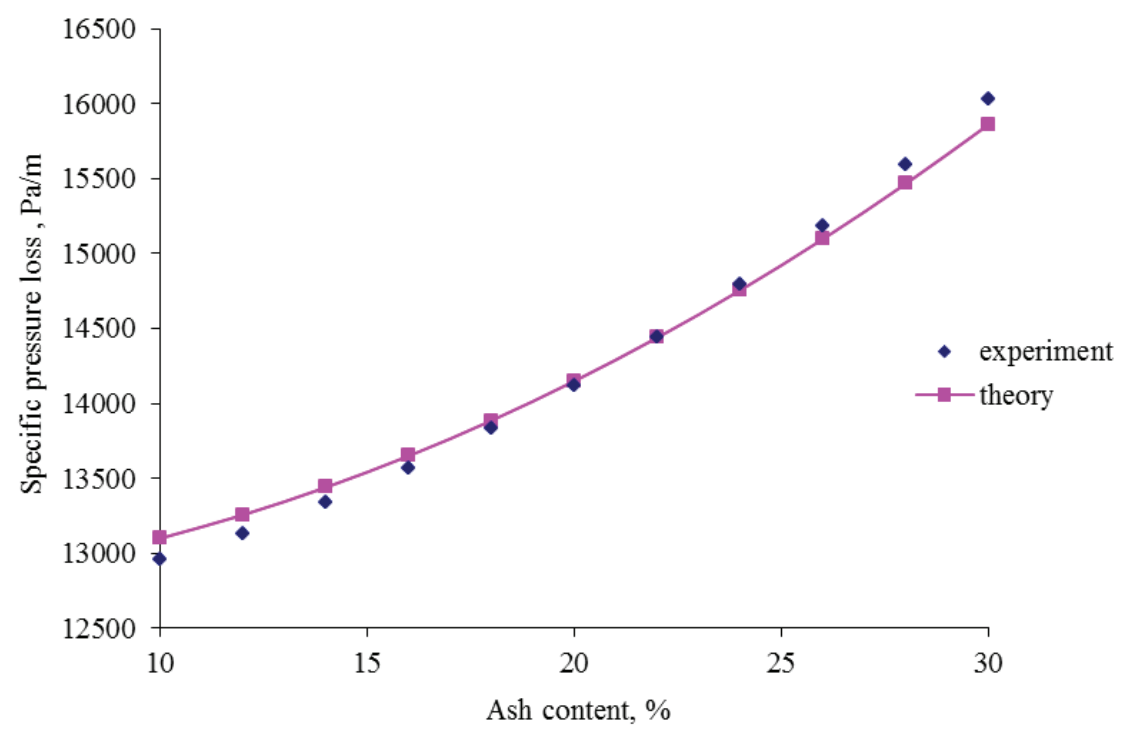

Fig. 3. Dependence of the specific pressure loss on the ash content of the original coal. 
A series of experiments determining the specific pressure loss was conducted to verify the correctness of the calculations. That allowed to analyse the convergence of the theoretical and experimental data (Fig. 3).

The graph in Figure 3 shows that the convergence of the theoretical and experimental data is satisfactory. This confirms the possibility of using the obtained dependences to predict the energy characteristics of the coal-water fuel flow, depending on the properties of the original coal.

\section{Conclusions}

The research results have as theoretical as applied nature. The obtained dependences enable to establish a connection between the rheological properties of the coal-water fuel and the physicochemical characteristics of the original coal. This provides possibility to assess the influence scale of the feedstock properties on the energy characteristics of the prepared of it water-coal fuel during transportation.

\section{References}

1. Dolinskiy, A.A., Halatov, A.A. (2007). Vodougolnoe toplivo: perspektivy ispolzovaniya v teploenergetike i zhilishchno-kommunalnom sektore. Promishlennaya teplotehnika. 29, 5, 70-79

2. Baranova, M.P., Kulahin, V.A. (2011). Fiziko-himicheskiye osnovy polucheniya vodougolnyh suspenziy. Krasnoyarsk: Sibirskiy federalniy universitet

3. Brahin B.F., Kolomiets, O.S. (1995). Pulpy ta suspenzii (tehnologii, ustatkuvannia, rozrahunki). Kyiv: ISDO

4. Murko, V.I. (1999). Nauchnye osnovy processov polucheniya i effektivnogo primeneniya vodougolnyh suspenziy. Moskva: Institut goriuchih iskopaemyh

5. Biletskyi, V.S., Krut, O.A., Svitlyi, Yu.G. (2005). Utilizatsiia vugilnyh shlamiv shliahom vygotovlennia vodovugilnogo palyva. Zbagachennia korisnyh kopalyn. 24(63), 111-118

6. Samoylik, V.G. (2014). Prognozirovaniye zavisimosti parametrov vodougolnogo topliva ot sostava i urovnia zolnosti tverdoy fazy. Zbagachennia korisnyh kopalyn. 58(99)-59(100)

7. Chernetskaya, N.B., Shvornikova, A.M., Varakuta, Ye.A., Bragin N.I. (2007). Issledovaniye reologicheskih harakteristik vodougolnogo topliva, sozdannogo na osnove ugley Donbassa. Visnyk Shidnoukrainskogo natsionalnogo universytetu imeni $V$. Dalia. [Visnik of the Volodymyr Dahl East Ukrainian National University], 3(109) 2, 213-219

8. Krut, O.A. (2002). Vodovugilne palyvo. Kyiv: Naukova dumka

9. Hodakov, G.S. (2007). Vodougolnye suspenzii v energetike. Teploenergetika. 1, 35-45

10. Hodakov, G.S. (2003). Reologiya suspenziy. Teoriya fazovogo techeniya i ee eksperimentalnoye obosnovaniye. Rossiyskiy himicheskiy zhurnal. XLVII, 2, 33-44.

11. Soroka, S.I. (2001). Reologiya zhidkosti. Lugansk: Izdatelstvo VNU im. V. Dalia

12. Ponomarev, S.V., Mishchenko, S.V., Divin, A.G. (2006). Teoreticheskiye prakticheskiye aspekty teplofizicheskih izmereniy. Tambov

13. Slyozkin, N.A. (1955). Dinamika viazkoy neszhimaemoy zhidkosti. Moskva: Mashinostroyeniye

14. Chernetskaya-Beletskaya, N.B., Baranov, I.O., Miroshnikova, M.V. (2017). Eksperimentalnye issledovaniya reologicheskih harakteristik i gidravlicheskih parametrov transportirovaniya vodougolnogo topliva. World science. 12(28), 1, 35-42 
15. Chernetskaya-Beletskaya, N., Guschin, O., Shvornikova, A., Baranov, I., Miroshnikova, M. (2017). Improving industrial pipeline transport using research of regularities of flow of mixtures in material pipeline. Vostochno-Evropeyskiy zhurnal peredovykh tekhnologiy [Eastern-European Journal of Enterprise Technologies], 4/7(88), 38-44

16. Chernetskaya-Beletskaya, N., Rogovyi, A., Shvornikova, A., Baranov, I., Miroshnikova, M., Bragin, N. (2018). Study on the coal-water fuel pipeline transportation taking into account the granulometric composition parameters. International Journal of Engineering \& Technology. 7 (4.3), 240-245 